\title{
Expression of hsa-miR-9 and $M Y C$ Copy Number Variation in Hereditary Diffuse Gastric Cancer
}

\author{
KELLY CRISTINA DA SILVA OLIVEIRA ${ }^{1}$, AMANDA BRAGA BONA ${ }^{2}$, FERNANDA JARDIM DA SILVA ${ }^{1}$, \\ THAYANNE MACEDO PINHEIRO ${ }^{1}$, DIEGO DI FELIPE AVILA ALCANTARA ${ }^{2}$, LETICIA MARTINS LAMARAO ${ }^{3}$, \\ CAROLINE AQUINO MOREIRA-NUNES ${ }^{2,4}$, PAULO PIMENTEL ASSUMPCAO ${ }^{1}$, \\ ROMMEL RODRIGUEZ BURBANO ${ }^{1,4,5}$ and DANIELLE QUEIROZ CALCAGNO ${ }^{1}$ \\ ${ }^{1}$ Oncology Research Center, Federal University of Para, Belem, Brazil; \\ ${ }^{2}$ Human Cytogenetics Laboratory, Institute of Biological Science, Federal University of Para, Belem, Brazil; \\ ${ }^{3}$ Hematology and Hemotherapy Center of Para, Belem, Brazil; \\ ${ }^{4}$ Pharmacogenomics Laboratory Nucleus of Research and Development of Medicines (NPDM), \\ Federal University of Ceara, Fortaleza, Brazil; \\ ${ }^{5}$ Molecular Biology and Human Cytogenetics Laboratory, Ophir Loyola Hospital, Belem, Brazil
}

\begin{abstract}
Background/Aim: Approximately, 15-50\% of families affected by hereditary diffuse gastric cancer (HDGC) exhibit CDH1 germline mutations. $C D H 1$ gene encodes $E$ cadherin, protein essential to the cell-cell contact of gastric epithelium. Studies have shown that hsa-miR-9 participates in this protein downregulation. Moreover, MYC is responsible for the transcription of hsa-miR-9-3. In the present study, hsamiR-9 expression and MYC copy number variation were investigated to elucidate the hsa-miR-9 role in HDGC. Patients and Methods: Tumor samples were obtained from nine individuals with HDGC history belonging to four Brazilian families. Then, relative quantification of hsa-miR9 expression and MYC gene copy number variation analysis were performed by real-time PCR. Results: In all the samples, an overexpression of hsa-miR-9 and an increased MYC copy number ( $\geq 3$ copies) were observed. Conclusion: hsa-miR-9 acts as an oncomiR in HDGC. In addition, we suggest that hsa-miR-9 acts as second event in individuals with HDGC carrying CDH1 gene germinline mutations.
\end{abstract}

Hereditary gastric cancer syndromes are responsible for 1$3 \%$ of gastric tumor cases $(1,2)$. Among the familial forms of gastric cancer (GC), hereditary diffuse gastric cancer (HDGC) is the only one with a well-defined genetic cause

Correspondence to: Danielle Queiroz Calcagno, Ph.D., Núcleo de Pesquisas em Oncologia, Hospital Universitário João de Barros Barreto/UNACON, Av. Mundurucus 4487, Belém, CEP: 66073-000, Brazil. Tel: +55 91 3201-6776, e-mail: danicalcagno@gmail.com

Key Words: CDH1, HDGC, miR-9, hereditary diffuse gastic cancer.
$(3,4)$. Approximately, $15-50 \%$ of families affected by HDGC are identified with germline mutations in the $C D H 1$. HDGC families individual members carrying $\mathrm{CDH} 1$ pathogenic mutations, have a risk of developing GC around $70 \%$ in men and $56 \%$ in women up to 80 years old (5).

CDH1 gene is located on chromosome 16q22.1 and encodes an epithelial cadherin protein (6). E-cadherin is a cellular adhesion protein that plays a critical role in cellular polarity and it is essential to the cell-cell contact of gastric epithelium, therefore suppressing invasion and acting as a tumor suppressor gene (7).

In the carcinogenesis context, a larger number of studies is focused on identifying key regulators of metastatic process, including microRNAs (miRNAs) $(8,9)$. miRNAs are small non-coding RNAs (19-25 nucleotides in length) that suppress gene expression by interaction with untranslated 3' region (UTR) of target mRNAs of genes involved in proliferation, differentiation and apoptosis. Thus, miRNAs exert a substantial influence in cancer pathogenesis (10-13).

Studies have demonstrated that hsa-miR-9 down-regulates $\mathrm{CDH1}$ expression in breast cancer, hepatocarcinoma and esophageal squamous cell carcinoma $(10,14)$. In humans, the mature hsa-miR-9 is encoded by three independent genetic loci (hsa-miR-9-1, hsa-miR-9-2 and hsa-miR-9-3) (15). In parallel, Ma et al. (12) demonstrated that MYC transcription factor is responsible for the transcription of hsa-miR-9-3.

MYC deregulation is considered crucial to gastric carcinogenesis, mainly due to genetic amplification $(16,17$, 19-24). Previously, our research group demonstrated an association between $M Y C$ overexpression with gastric adenocarcinoma invasion and metastasis $(24,25)$. Therefore, $M Y C$ can influence the hsa-miR-9 expression which, in turn, 
could negatively regulate the $C D H I$ expression. In this study, the hsa-miR-9 expression and $M Y C$ copy number variation were evaluated, for the first time, to elucidate the hsa-miR9 role in HDGC.

\section{Patients and Methods}

HDGC Families/Samples. Gastric tumor samples were obtained from nine individuals with HDGC history belonging to four North and Northeast Brazilian families selected according to the latest International Consortium of Gastric Cancer (26). Additionally, a retrospective study of family members was conducted to identify affected members by these tumors and other cancer types in previous generations (Figure 1).

The molecular analysis was performed in paraffin embedded tissue from gastric tumor and paired adjacent non-neoplastic gastric samples using micro-dissection. This study was approved by the Research Ethics Committee of João de Barros Barreto University Hospital (HUJBB) under protocol 274/12 and all patients analyzed signed a consent statement.

Relative quantification of hsa-miR-9 expression. Formalin-fixed, paraffin-embedded (FFPE) tissue samples were deparaffinized and underwent miRNA extraction using miRNeasy FFPE Kit (Qiagen, Hilde, Germany) according to the manufacturer's instructions. miRNA yield was determined through a NanoDrop ND-1000 spectrophotometer (Thermo Scientific, Wilmington, DE, USA), and the quality was assessed by $1 \%$ agarose gel electrophoresis.

Reverse transcription was performed using TaqMan Small RNA Assays kit (Applied Biosystems, Foster City, CA, EUA), according to the manufacturer's recommendations. Immediately, the cDNA obtained was stored at $-20^{\circ} \mathrm{C}$ and, posteriorly, they were mixed in 96well plates with $7.5 \mu \mathrm{l}$ of 1x TaqMan Universal PCR Master Mix II (Life Technologies, Carlsbad, CA, EUA) and $0.5 \mu 1$ of TaqMan ${ }^{\circledR}$ Advanced miRNA Assays for hsa-miR-9 (478214_mir) (Life Technologies, Carlsbad, CA, EUA), according to the manufacturer's recommendations. SNORD7 (Hs03298738_s1) assay (Life Technologies, Carlsbad, CA, EUA) was selected as an internal control for monitoring RNA input and reverse transcription efficiency.

Copy number variation $(C N V)$. DNA was extracted using a QIAamp DNA FFPE tissue kit (Qiagen, Hilden, Germany) according to the manufacturer's instructions. Duplex quantitative real-time PCR (real-time qPCR) was performed using the FAM/MGB-labeled TaqMan probes for MYC (Hs01764918_cn) and VIC/TAMRAlabeled TaqMan CNV RNAse P (\#4403326) was used for the internal control. All real-time qPCR reactions were performed in quadruplicate with gDNA according to the manufacturer's protocol using a 7500 Fast Real-Time PCR system (Life Technologies, Foster City, CA, USA). The copy number of each sample was estimated by CNV analysis using Copy Caller Software V1.0 (Life Technologies, Foster City, CA, USA). Known Human Genomic DNA (Promega, Madison, WI, USA) was used for calibration.

Statistical analysis. The normality of variable distributions was determined using the Shapiro-Wilk test. Association between hsamiR-9 expression and clinical pathological features were analyzed using the Mann-Whitney tests. $p$-Values less than 0.05 were considered significant.

\section{Results}

Overexpression of hsa-miR-9 was observed in HDGC tumor samples $(1.78 \pm 0.50$; median \pm interquartile range) compared with parried non-neoplastic adjacent tissue samples. The difference in expression of hsa-miR-9 between families with (1.55 \pm 0.02$)$ and without $\mathrm{CDH} 1$ germline mutations $(2.15 \pm 0.17)$ was not statistically significant $(\mathrm{p}=0.0706)$ (Figure 2). Additionally, an increase in copy number variation of MYC gene ( $\geq 3$ copies) was observed in HDGC families analyzed.

\section{Discussion}

Mutations in the $C D H 1$ gene affect protein integrity, thereby, causing disturbances in cell-cell adhesion on epithelial tissues, enhancing the cellular motility and potentiating the infiltrative tumor behavior and metastasis development (27-29).

In gastric carcinogenesis, loss of E-cadherin expression is a common event and is associated with disease aggressiveness and poor prognosis (27). However, the molecular mechanisms underlying the invasive process, associated to E-cadherin dysfunction, are far from being understood (27-30).

Moreira-Nunes et al. (31) were the first study to evaluate germline mutations in the $\mathrm{CDHl}$ gene simultaneously with the methylation pattern of promoter region and E- cadherin expression in Brazilian families with HDGC. Despite the absence of E-cadherin expression found in all families, the CDH1 gene promoter region was not methylated and mutations were observed only in $50 \%$ (2/4) of the evaluated families. Moreover, the Comparative Genomic Hybridization analysis (aCGH) showed no gains or losses events, suggesting that other mechanisms could be involved in the E-cadherin expression silencing.

The present study investigated the hsa-miR-9 expression in HDGC families previously analyzed by Moreira-Nunes et al. (31), with the aim of elucidating the involvement of this miRNA in E-cadherin negative regulation. It was observed hsa-miR-9 overexpression in HDGC (1.78 \pm 0.50$)$ compared to paired adjacent non-neoplastic specimens. Although higher hsa-miR-9 levels were observed in samples of families' members without germline mutation in $C D H 1$ gene $(2.15 \pm 0.17)$, the difference of hsa-miR-9 expression was not statistically significant independently of germline mutations in CDH1 $(p=0.0706)$. Thus, these results suggest an oncomiR role of hsa-miR-9 in HDGC and this implies a negative regulation of E-cadherin regardless of the presence of germline mutation in the $C D H 1$ gene.

Several studies have described that hsa-miR-9 expression levels are significantly associated with different diseases, including breast cancer, ovarian cancer, renal cell carcinoma and GC (32-36). Moreover, studies have shown a strong 
A

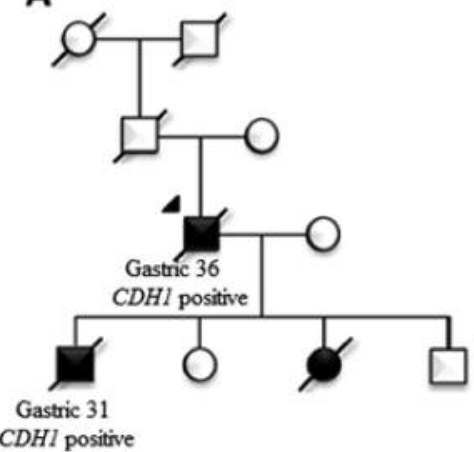

B

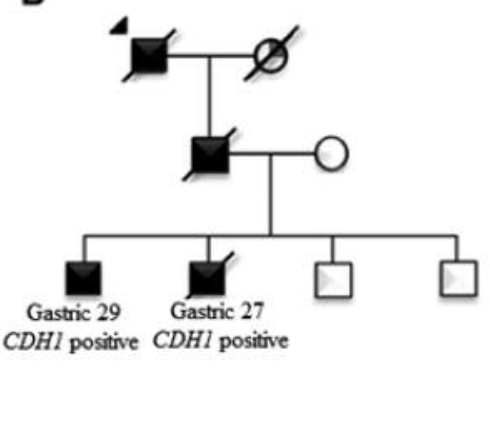

D

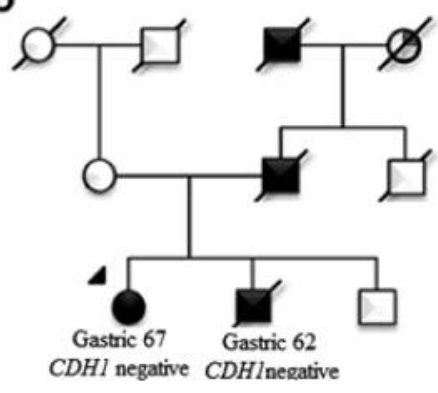

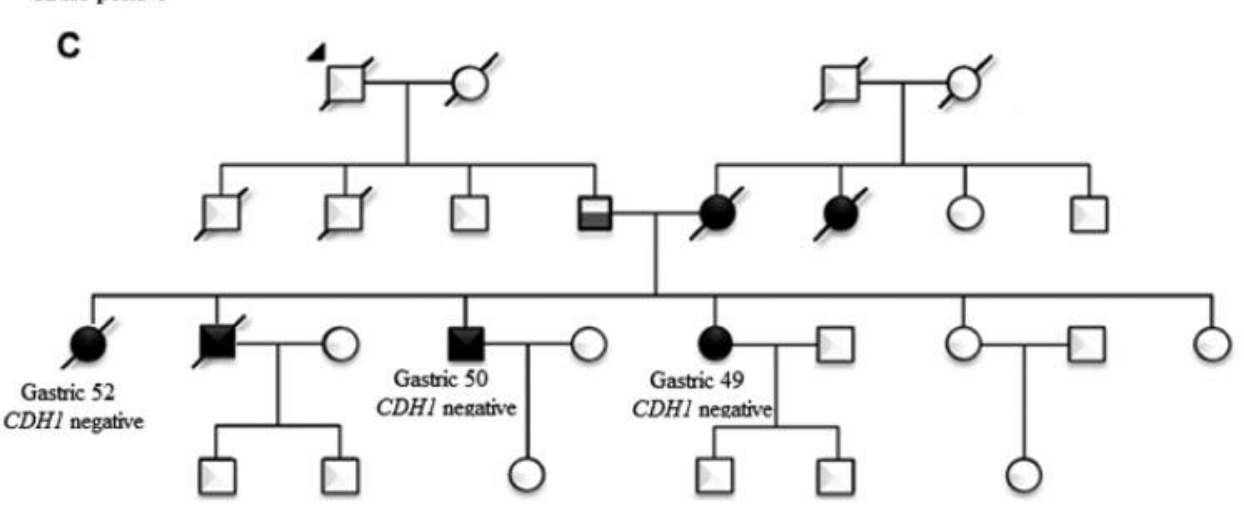

Figure 1. Pedigrees charts of hereditary diffuse gastric cancer families. $(A),(B),(C)$ and $(D)$ represent the four families presented in this study. The numbers under the symbols represent the age at diagnosis. The solid symbols correspond to the affected members with confirmed diffuse GC diagnoses. Upper left arrows indicate the probands. $\mathrm{CDH1}$ positive represent members carrying CDH1 gene germline mutations, and CDH1 negative are members without CDH1 gene germline mutations described by Moreira-Nunes et al. (2014).

correlation of these expression levels with pathologic clinical conditions, as tumor stage, metastasis and survival outcome $(15,32,36-39)$.

In GC, Rotkua et al. (40) concluded that hsa-miR-9 was positively expressed in GC samples and could be involved in gastric carcinogenesis via CDX2 downregulation, resulting in promotion of cell growth. In the other hand, Luo et al. (31) and Zheng et al. (41) demonstrated reduced levels of hsa-miR-9 in tumor samples relative to non-neoplastic tissue and concluded that this miRNA suppresses the expression of cyclin D1 and ETS1, inhibiting the proliferation, invasion and metastasis. Thus, the hsa-miR-9 has a controversial role in gastric carcinogenesis.

These conflicting data of hsa-miR-9 expression could be related to the differential processing of mature $h s a-m i R-9$ from three primary precursors, $h s a-m i R-9-1, h s a-m i R-9-2$ and $h s a-$ miR-9-3. Negative adjustments in precursor regions, due to aberrant hypermethylation have been reported by independent studies in different types of cancer $(15,37,42-43)$.

Additionally, it is important to highlight that hsa-miR-9-3 transcript is up-regulated by the MYC transcription factor (12). This transcription factor is an important regulator of metabolism and cell proliferation and it is usually found deregulated in GC $(12,20-25,44-45)$.

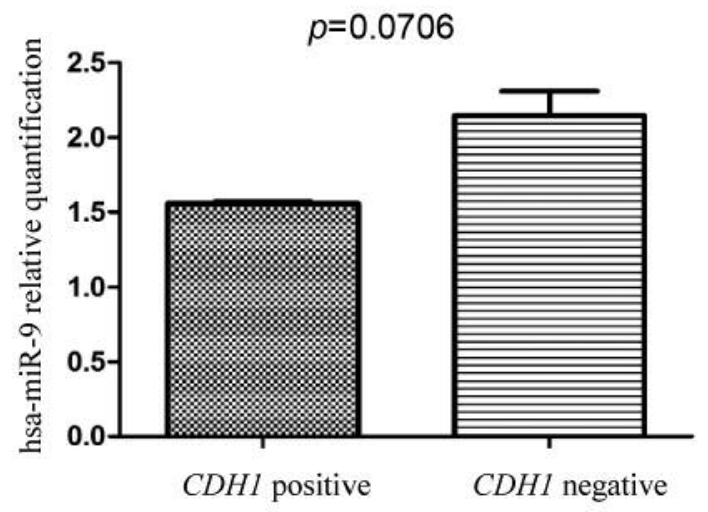

Figure 2. Relative quantification of hsa-miR-9 expression in HDGC families. The difference in expression of hsa-miR-9 between families carrying $\mathrm{CDH} 1$ gene germline mutations ( $\mathrm{CDH} 1$ positive) and without CDH1 germline mutations (CDH1 negative) was not statistically significant $(p=0.0706)$.

In the current study, $M Y C$ gene copy number variation increase ( $\geq 3$ copies) was observed in HDGC analyzed samples. These findings corroborate with Ma et al. (12) that proposed $M Y C$ as a transcriptional factor to hsa-miR-9-3 


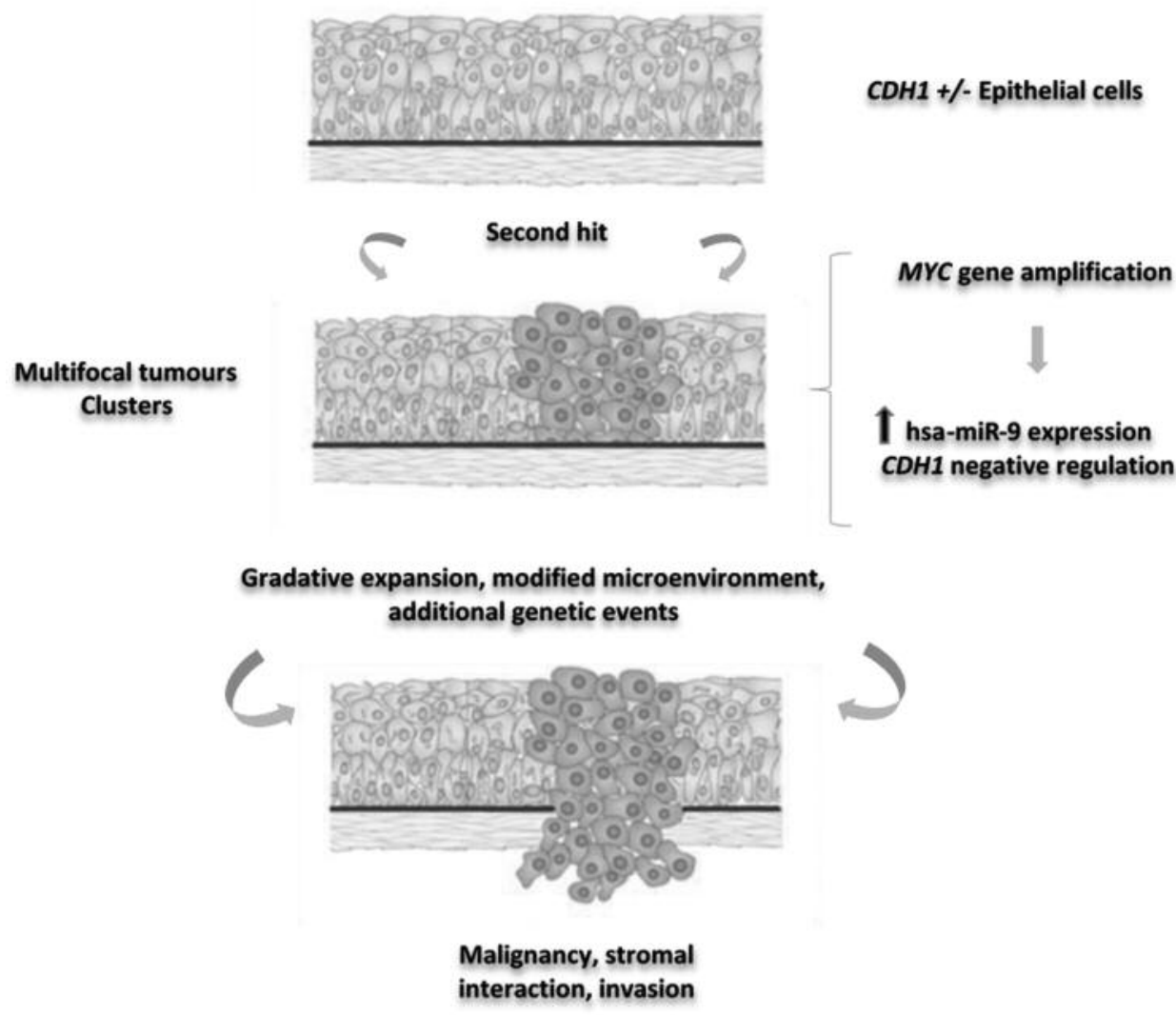

Figure 3. The hsa-miR-9 action as a second hit mechanism in two hits hypothesis in CDH1 gene germline mutations carriers. (A) Epithelial cells with CDH1 germline mutations as first hit loose cell-cell adhesion and gain epithelial-mesenquimal transition characteristic. (B) In GC, MYC gene amplification is a frequent event and this gene acts regulating positively the hsa-miR-9. In turn, the hsa-miR-9 overexpression is responsible to regulates negatively the CDH1 gene. Thus, spontaneous tumors clusters emerges. (C) Consecutively, the microenvironment is altered generating progressive cell growth and additional genetic events enable the installation of malignancy with stromal interaction and invasion.

locus, causing activation of mature hsa-miR-9 expression in tumors cells (43-44). Furthermore, these authors suggested that mature hsa-miR-9 can suppress E-cadherin expression resulting in motility promotion of carcinoma cells with invasion ability.

\section{Conclusion}

In summary, hsa-miR-9 was overexpressed in all samples of HDGC compared to paired adjacent non-neoplastic tissue, suggesting that this miRNA would play an oncomiR role. Moreover, MYC amplification was observed in the HDGC analyzed samples.

Therefore, considering the classic two-hits hypothesis (46), this study suggests that the second hit occurrence and, consequently, the total inactivation of E-cadherin protein, would be the hsa-miR-9 deregulation expression as result of MYC amplification in HDGC samples of the families' members carrying $\mathrm{CDH} 1$ germinal mutation (Figure 3 ).

\section{Acknowledgements}

This study was supported by the National Council for Scientific and Technological Development (CNPq; to ABB, RRB, PPM) and the Coordination of Improvement of Higher Level Personnel (CAPES; to $\mathrm{KCSO}, \mathrm{ABB}, \mathrm{DDFAA}, \mathrm{CAMN})$.

\section{References}

1 Colvin H, Yamamoto K, Wada N and Mori M: Hereditary Gastric Cancer Syndromes. Surg Oncol Clin N Am 24: 765-777, 2015.

2 Bresciani C, Perez RO and Gama-Rodrigues J: Familial gastric cancer. Arq Gastroenterol 40: 114-117, 2003.

3 Guilford P, Blair V, More H and Humar B: A short guide to hereditary diffuse gastric cancer. Hered Cancer Clin Pract 5: 183-194, 2007.

4 Hansford S, Kaurah P, Li-Chang H, Woo M, Senz J, Pinheiro H, Schrader KA, Schaeffer DF, Shumansky K, Zogopoulos G, Santos TA, Claro I, Carvalho J, Nielsen C, Padilla S, Lum A, Talhouk A, Baker-Lange K, Richardson S, Lewis I, Lindor NM, Pennell E, MacMillan A, Fernandez B, Keller G, Lynch H, Shah SP, Guilford 
P, Gallinger S, Corso G, Roviello F, Caldas C, Oliveira C, Pharoah PD and Huntsman DG: Hereditary diffuse gastric cancer syndrome: $C D H 1$ mutations and beyond. JAMA 1: 23-32, 2015.

5 Huynh JM and Laukaitis CM: Panel testing reveals nonsense and missense $\mathrm{CDH} 1$ mutations in families without hereditary diffuse gastric cancer. Mol Genet Genomic Med 4: 232-236, 2016.

6 Calcagno DQ, Gigek CO, Chen ES, Burbano RR and Smith Mde A: DNA and histone methylation in gastric carcinogenesis. World J Gastroenterol 19: 1182, 2013.

7 Van Roy F and Berx G: The cell-cell adhesion molecule E-cadherin. Cell Mol Life Sci 65: 3756-3788, 2008.

$8 \mathrm{Xu} \mathrm{Y,} \mathrm{Sun} \mathrm{J,} \mathrm{Xu} \mathrm{J,} \mathrm{Li} \mathrm{Q,} \mathrm{Guo} \mathrm{Y} \mathrm{and} \mathrm{Zhang} \mathrm{Q:} \mathrm{miR-21} \mathrm{is} \mathrm{a}$ promising novel biomarker for lymph node metastasis in patients with gastric cancer. Gastroenterol Res Pract 2012: 640168, 2012.

9 Calcagno DQ, de Arruda Cardoso Smith M and Burbano RR: Cancer type-specific epigenetic changes: gastric cancer. Canc Epig: R Ass, Diag, Trea, and Prog 1238: 79-101, 2015.

10 Malumbres M: miRNAs and cancer: an epigenetics view. Mol Aspects Med 34: 863-874, 2013.

11 Oliveira KCS, Araújo TMT, Albuquerque CI, Barata GA, Gigek CO, Leal MF, Wisnieski F, Mello Junior FAR, Khayat AS, Assumpção PP, Burbano RMR, Smith MC and Calcagno DQ: Role of miRNAs and their potential to be useful as diagnostic and prognostic biomarkers in gastric cancer. World $\mathrm{J}$ Gastroenterol 22: 7951-7962, 2016.

12 Ma L, Young J, Prabhala H, Pan E, Mestdagh P, Muth D, Teruya-Feldstein J, Reinhardt F, Onder TT, Valastyan S, Westermann F, Speleman F, Vandesompele J and Weinberg RA: miR-9, a MYC/MYCN-activated microRNA, regulates Ecadherin and cancer metastasis. Nature Rev Mol Cell Biol 12: 247-256, 2010.

13 Martins NNF, Oliveira KCS, Bona AB, Smith MAC, Ishak G, Assumpção PP, Burbano RR and Calcagno DQ: The Emerging Role of miRNAs and Their Clinical Implication in Biliary Tract Cancer. Gastroenterol Res Pract 2016: 9797410, 2016.

14 Drakaki A, Hatziapostolou M, Polytarchou C, Vorvis C, Poultsides GA, Souglakos J, Georgoulias V and Liopoulos D: Functional microRNA high throughput screening reveals miR-9 as a central regulator of liver oncogenesis by affecting the PPARA-CDH1 pathway. BMC Cancer 15: 542, 2015.

15 Tsai KW, Liao YL, Wu CW, Hu LY, Li SC, Chan WC, Ho MR, Lai CH, Kao HW, Fang WL, Huang KH and Lin WC: Aberrant hypermethylation of miR-9 genes in gastric cancer. Epig 6: 1189-1197, 2011.

16 Tao J, Zhao X and Tao J: c-MYC-miRNA circuitry: a central regulator of aggressive B-cell malignancies. Cell Cycle 13: 191198, 2014.

17 Panani AD: Cytogenetic and molecular aspects of gastric cancer: clinical implications. Cancer Lett 26: 99-115, 2008.

18 Nagini S: Carcinoma of the stomach: A review of epidemiology, pathogenesis, molecular genetics and chemoprevention. World J Gastrointest Oncol 7: 156-169, 2012.

19 Vauhkonen M: Pathology and molecular biology of gastric cancer. Best Pract Res Clin Gastroenterol 20: 651-674, 2006.

20 Calcagno DQ, Leal MF, Taken SS, Assumpção PP, Demachki S, Smith Mde A and Burbano RR: Aneuploidy of chromosome 8 and C-MYC amplification in individuals from northern Brazil with gastric adenocarcinoma. Anticancer Res 25: 4069-4074, 2005.
21 Calcagno DQ, Leal MF, Seabra AD, 1 Khayat AS, Chen ES, Demachki S, Assumpção PP, Faria MH, Rabenhorst SH, Ferreira MV, de Arruda Cardoso Smith M and Burbano RR: Interrelationship between chromosome 8 aneuploidy, C-MYC amplification and increased expression in individuals from northern Brazil with gastric adenocarcinoma. World J Gastroenterol 12: 6207, 2006.

22 Calcagno DQ, Leal MF, Assumpcao PP, Smith MA and Burbano RR: MYC and gastric adenocarcinoma carcinogenesis. World J Gastroenterol 14: 5962-5968, 2008.

23 Costa Raiol LC, Figueira Silva EC, Mendes da Fonseca D, Leal MF, Guimarães AC, Calcagno DQ, Khayat AS, Assumpção PP, de Arruda Cardoso Smith M and Burbano RR: Interrelationship between MYC gene numerical aberrations and protein expression in individuals from northern Brazil with early gastric adenocarcinoma. Cancer Genet Cytogenet 181: 31-35, 2008.

24 Calcagno DQ, Freitas VM, Leal MF, de Souza CR, Demachki S, Montenegro R, Assumpção PP, Khayat AS, Smith MAC, dos Santos AK and Burbano RR: MYC, FBXW7 and TP53 copy number variation and expression in gastric cancer. BMC Gastroenterol 13: 141, 2013.

25 De Souza CR, Leal MF, Calcagno DQ, Costa Sozinho EK, Borges Bdo N, Montenegro RC, Dos Santos AK, Dos Santos SE, Ribeiro HF, Assumpção PP, de Arruda Cardoso Smith M and Burbano RR: MYC deregulation in gastric cancer and its clinicopathological implications PLoS One 8: e64420, 2013.

26 Fitzgerald RC, Hardwick R, Huntsman D, Carneiro F, Guilford P, Blair V, Chung DC, Norton J, Ragunath K, Krieken JHV, Dwerryhouse $\mathrm{S}$ and Caldas C: Hereditary diffuse gastric cancer: updated consensus guidelines for clinical management and directions for 1 future research. J Med Genet 47: 436-444, 2010.

27 Mateus AR, Simões-Correia J, Figueiredo J, Heindl S, Alves CC, Suriano G, Luber B and Seruca R: E-cadherin mutations and cell motility: a genotype-phenotype correlation. Exp Cell Res 315: 1393-1402, 2009.

28 El-Husny A, Raiol-Moraes M, Amador M, Ribeiro-Dos-Santos AM, Montagnini A, Barbosa S, Silva A, Assumpção P, Ishak G, Santos S, Pinto P, Cruz A and Ribeiro-Dos-Santos Â: CDH1 mutations in gastric cancer patients from northern Brazil identified by Next-Generation Sequencing (NGS). Int J Genet Mol Biol 39: 189-198, 2016.

29 Ghaffari SR, Rafati M, Sabokbar T and Dastan J: A novel truncating mutation in the E- cadherin gene in the first Iranian family with hereditary diffuse gastric cancer. Eur J Surg Oncol 36: 559-562, 2010.

30 Caldeira J, Figueiredo J, Brás-Pereira C, Carneiro P, Moreira AM, Pinto MT, Relvas JB, Carneiro F, Barbosa M, Casares F, Janody $\mathrm{F}$ and Seruca R: E-cadherin-defective gastric cancer cells depend on Laminin to survive and invade. Hum Mol Gen 24: 5891-5900, 2015.

31 Moreira-Nunes CA, Leão Barros MB, Borges BN, Montenegro RC, Lamarão LM, Ribeiro HF, Bona AB, Assumpção PP, Rey JA, Pinto GR and Burbano RR: Genetic screening analysis of patients with hereditary diffuse gastric cancer from northern and northeastern Brazil. Hered Cancer Clin Pract 12: 18, 2014.

32 Luo H, Zhang H, Zhang Z, Zhang X, Ning B, Guo J, Nie N, Liu $\mathrm{B}$ and $\mathrm{Wu} \mathrm{X}$ : Down-regulated miR-9 and miR-433 in human gastric carcinoma. J Exp Clin Cancer Res 28: 1, 2009.

33 Guo LM, Pu Y, Han Z, Liu T, Li YX, Liu M, Li X and Tang H: MicroRNA-9 inhibits ovarian cancer cell growth through regulation of NFkB1. FEBS journal 276: 5537-5546, 2009. 
34 Hildebrandt MA, Gu J, Lin J, Ye Y, Tan W, Tamboli P, Wood CG and $\mathrm{Wu} \mathrm{X}$ : Hsa-miR-9 methylation status is associated with cancer development and metastatic recurrence in patients with clear cell renal cell carcinoma. Oncogene 29: 5724-5728, 2010.

35 Selcuklu SD, Donoghue MT, Rehmet K, de Souza Gomes M, Fort A, Kovvuru P, Muniyappa MK, Kerin MJ, Enright AJ and Spillane C: MicroRNA-9 inhibition of cell proliferation and identification of novel miR-9 targets by transcriptome profiling in breast cancer cells. J Biol Chem 287: 29516-29528, 2012.

36 Deng J, Lei W, Xiang X, Zhang L, Lei J, Gong Y, Song M, Wang Y, Fang Z, Yu F, Feng M, Sun Z, Chen J, Zhan Z and Xiong J: Cullin 4A (CUL4A), a direct target of miR-9 and miR137 , promotes gastric cancer proliferation and invasion by regulating the Hippo signaling pathway. Oncotarget 7: 1003710050, 2016.

37 Bandres E, Agirre X, Bitarte N, Ramirez N, Zarate R, RomanGomez J, Prosper F and Garcia-Foncillas J: Epigenetic regulation of microRNA expression in colorectal cancer. Int J Cancer 125: 2737-2743, 2009.

38 Laneve P, Gioia U, Andriotto A, Moretti F, Bozzoni I and Caffarelli E: A minicircuitry involving REST and CREB controls miR-9-2 expression during human neuronal differentiation. Nucleic Acids Res 38: 6895-6905, 2010.

39 Edmonds MD and Eischen CM: Differences in miRNA expression in early stage lung adenocarcinomas that did and did not relapse. PloS one 9: e101802, 2014.

40 Rotkrua P, Akiyama Y, Hashimoto Y, Otsubo T and Yuasa Y: MiR-9 down-regulates CDX2 expression in gastric cancer cells. Int J Cancer 129: 2611-2620, 2011.
41 Zheng L, Qi T, Yang D, Qi M, Li D, Xiang X, Huang K and Tong Q: microRNA-9 suppresses the proliferation, invasion and metastasis of gastric cancer cells through targeting cyclin D1 and Ets1. PloS one 8: e55719, 2013.

42 Hsu PY, Deatherage DE, Rodriguez BA, Liyanarachchi S, Weng YI, Zuo T, Liu J, Cheng AS and Huang TH: Xenoestrogeninduced epigenetic repression of microRNA-9-3 in breast epithelial cells. Cancer Res 69: 5936-5945, 2009.

43 Wan HY, Guo LM, Liu T, Liu M, Li X and Tang H: Regulation of the transcription factor NF-kB1 by microRNA-9 in human gastric adenocarcinoma. Mol Cancer 9: 1, 2010.

$44 \mathrm{Li}$ Y, Nie Y, Cao J, Tu S, Lin Y, Du Y and Li Y: G-A variant in miR-200c binding site of EFNA1 alters susceptibility to gastric cancer. Mol Carcinog 53: 219-229, 2014.

45 Mclean MH and El-Omar EM: Genetics of gastric cancer. Nat Rev Gastroenterol Hepatol 11: 664-674, 2014.

46 Knudson AG: Mutation and cancer: statistical study of retinoblastoma. Proc Natl Acad Sci USA 68: 820-823, 1971.
Received March 22, 2017

Revised April 11, 2017

Accepted April 12, 2017 